\title{
Application Strategy of Laser Welding and Cutting Technology in Automobile Manufacturing
}

\author{
Teng Wan \\ College of Mechanical Engineering, Baicheng Normal University, Baicheng City, Jilin Province,137000, \\ China
}

Keywords: automobile manufacture; laser welding; laser cutting; application

\begin{abstract}
As an advanced manufacturing technology, laser processing technology has been widely used in various industries. Although the technology of laser welding and cutting has made great progress in China, there is still a big gap in the application of laser welding and cutting in automobile manufacture compared with foreign developed countries. At present, it is mainly to introduce complete sets of laser processing equipment, production lines and technologies for welding and cutting automobile welding panels and body components. Some manufacturers directly import parts and components from foreign laser processing, which will hinder the application and popularization of laser and reduce the level of laser industrialization. Based on the author's study and practical experience, this paper first analyzed the laser processing technology in automobile manufacturing, then discussed the specific application of laser processing in automobile manufacturing, and finally summarized the application of new welding technology in automobile manufacturing.
\end{abstract}

\section{Introduction}

Welding is one of the four links that must be experienced in the process of automobile manufacture. Manual welding technology is used in traditional automobile manufacturing, however, with the development of national technology and the improvement of scientific level, manual welding technology has been unable to meet the increasing demand for automobiles. As a result, domestic automobile manufacturing enterprises have introduced new welding technology one after another to promote the upgrading of automobile manufacturing power. In order to improve the advanced technical capability of automobile manufacturing in our country, we should rely on the domestic technical strength, innovate ourselves and accelerate the application and development of laser processing in automobile manufacturing industry in a wider range and deeper level. It is still a very difficult task to expand and improve the industrial application and industrialization level of laser processing technology.

\section{Laser Processing Technology in Automobile Manufacturing}

\subsection{Principle of laser welding}

Laser welding technology is a kind of automatic welding technology which takes laser as welding source. The heat source of the laser is used to control most of the heat source in a very small part, which can accelerate the connection of the welding position. At a certain power, the laser can quickly heat the specified part of the metal, vaporize the surface of the metal, and then fall off the surface of the metal. In the process of gasification, when the stress is added to the surface of the metal, the surface will appear the phenomenon of depression. Further lasers can hit the bottom of the depression, producing holes that are both small and thin, and as the laser moves, the holes also move toward the welding direction. When the metal melts in front of the hole, the rear of the hole resolidifies and the weld are created. The laser power density determines the depth of the weld. If the laser power density is high, the penetration depth will be larger, and the weld depth and width will be larger. On the contrary, if the laser power density is lower, the penetration depth will be 
shallow, and the weld depth width will be smaller.

\subsection{Development of laser processing technology in automobile manufacturing}

In the beginning of 90s, the national automobile industry is still in the primary stage of development. Only a part of the automobile enterprises used laser welding technology in the manufacturing process, at this time, the laser welding was only used in the automobile chassis and automobile body welding. With the development of laser technology, more and more domestic automobile enterprises choose laser welding technology, laser processing technology is also applied to more automobile manufacturing links. The noise of the laser technology is small, and the laser welding can effectively improve the stability of the car, which will maximize the safety and robustness of the driving process, therefore, laser processing technology has gradually replaced the traditional manual welding mode. Although the country has made outstanding achievements at the present stage, the welding technology still needs to be further developed, so that more automobile manufacturers can understand laser processing technology. With the development of laser welding technology, three dimensional laser cutting technology is developing continuously. It has been widely used in various industrial manufacturing industries, especially in automobile manufacturing and aviation manufacturing. In the national automobile industry at present, 3D laser cutting technology is usually applied to the whole abandoned car body cutting, and the application of laser cutting technology can effectively reduce the working time and cost of automobile manufacturing. It has a good industrial technology development prospects.

\section{Application of Laser Machining in Automobile Manufacturing}

\subsection{Application of Laser Welding in Automobile Manufacture}

(1) Laser Tailor Welding of vehicle body Plate with unequal thickness. In addition to considering performance and price in the process when buying a car, the design and shape of the car body is also an important factor determining the purchase of a car by consumers. Therefore, in the process of body design and manufacture, the plate with different thickness, material and performance should be connected, and the application of laser welding technology can help the manufacturer to complete the splicing better. The application of laser splicing technology can reduce the consumption of parts and models, and reduce the workflow, which has been widely used at this stage. In 1985, German steel company and German Volkswagen company successfully used laser splicing technology in the chassis splicing for Audi sedan. Then the laser welding technology has been widely used, by 1990s, the TWB technology can reduce $1 / 4$ of the body parts by laser. At this stage, laser welding technology is not only applied to the chassis, but also applied to all parts of the car body. For example, a car manufacturing enterprise, may apply laser tailor - welding technology in the automobile interior trunk reinforcement panel, shock absorber support, bumper and other parts. Compared with the development of automobile manufacturing industry in foreign countries, China's laser tailor - welded plate technology is not formal before 2002. At present, the technology of laser welding board developed in China adopts the core technology and equipment of Germany and Japan, and the country needs further development in the aspect of independent research and development. Laser welding board technology have been fully applied in Audi, Buick, Passat and other high-grade cars.

(2) Laser welding of car body assembly and sub-assembly. Not only splicing plate technology, but laser welding technology has been used in the field of automobile body manufacture since it was put forward in 1980s. It is mainly responsible for welding between body assembly and sub-assembly. The application of laser resistance welding technology can fundamentally improve the speed and quality of welding, so it has been widely used. The proposal of group welding technology has also changed the monopoly position of traditional welding technology in the field of automobile body manufacturing. This technology can effectively improve the assembly accuracy and stiffness of automobile body, and achieve the purpose of energy saving and emission reduction. The improvement of body performance also ensures the safety and stability in the process of vehicle 
use. In the process of laser welding of automobile body, the degree of body integration can be improved by reducing the stamping and assembly cost produced in body manufacture. Compared with conventional welded cars, such vehicles will produce less noise and vibration in the course of driving, and will increase the driver's driving comfort. The welding process includes assembly welding, side position, top welding, and automobile welding. At this stage, many automobile brands have adopted this laser welding technology, such as Dongfeng Peugeot, Touran, etc. Among them, FAW Volkswagen's all brand models used different degrees of laser welding technology. This technique is used in the welding of the top cover and rear cover of Audi A6, and the laser welding technology is also used in Touran. The length of the weld is up to 40 meters.

(3) Laser Welding in Automobile parts. Not just the body, but also the parts of the car that use laser welding. By using the welding technology, the welding speed and the welding efficiency of the parts can be improved, and the integrity of the parts will be ensured. For example, car transmission shaft, supercharger, door hinge and so on can be used laser welding technology.

\subsection{Application of laser cutting in automobile manufacturing}

In addition to laser welding technology, laser cutting technology has been developed since 1920s. There is still a certain distance between the laser cutting technology in China and the developed countries. It is necessary to carry out self-development projects while introducing foreign advanced technology to promote the progress and development of the national laser cutting technology. By using 3D laser cutting technology, we can simplify the process steps and shorten the manufacturing cycle. With the increase of cutting speed, the quality of automobile processing will be also improved. The application of this technology can lead to the continuous innovation in the national automobile industry. At present, three dimensional laser cutting machine is mainly used, and the application of laser cutting technology in foreign countries is more common, including the development of new models, deformed cars and other production links. Using laser cutting technology to cut steering wheel and body baffle of prototype car, and this cutting technology is conducive to the current stage of changing vehicle demand. For example, Hunan university and a car company in shanghai have developed a large three-dimensional laser cutting machine. Not only that, many universities have also carried out research on cutting technology.

\section{Application of New Welding Technology in Automobile Manufacturing}

\subsection{Laser composite welding technology}

Laser hybrid welding technology combines laser with other heat sources on the basis of laser welding, which can further improve the welding effect, speed up the welding and improve the ability of welding and bridging.

\subsection{Laser remote welding technology}

The traditional laser welding system needs to move rapidly in the welding position, and it is difficult to meet the requirements of production in the actual production process, so the remote welding technology is put forward. The remote laser welding is gradually replacing the traditional laser welding technology at present, but it is still in the concept development stage in our country, so it needs further improvement to improve the automobile production output.

\section{Conclusions}

With the improvement of the people's living standards, the needs of the people are also changing. In the manufacturing process, the actual needs of the users will be taken as the main reference for the manufacture and design, and the laser technology will give the automobile industry a good opportunity for development. Therefore, all automobile manufacturing enterprises need to further strengthen the research and application of laser technology innovation. 


\section{References}

[1] Tong Chi. Application Analysis of Laser Welding and cutting in Automobile Manufacturing [J]. An era Automotive car, 2017, (24): 70-71.

[2] Ma Chuangang. Application of laser welding and cutting in automobile manufacturing[J]. Agricultural Machinery of the Times, 2016, (04): 29+31.

[3] Chen Zheng. Application of laser welding and cutting in automobile manufacturing[J]. modern manufacturing technology and equipment, 2016, (04): 111-112.

[4] Chen Ganyu, Mei Li-fang. Application of laser welding and cutting in automobile manufacturing[J]. Progress in Laser and Optoelectronics, 2009, (09): 17-23.

[5] Tian Han. Application of laser technology in metal material processing [J]. Technology and Market: 201623 / 11: 103.

[6] Lang Xuyuan. Application of laser technology in automobile industry[J]. Mechanical engineer, 2006, (06): 20-23.

[7] Gu Yine. Application of laser technology in processing of metal materials[J]. Information recording material, 2018, 19(02): 15-16. 